\title{
Identification of $\mathrm{X}$ - and $\mathrm{Y}$-chromosome-bearing human sperm separated by free-flow electrophoresis using Y-chromosome-specific polymerase chain reaction
}

\author{
Sanae A. Ishijima ${ }^{1}$, Makoto Okuno ${ }^{1}$, Yutaka Nakahori ${ }^{2}$, Satoko Seki ${ }^{2}$, Sigeo Nagafuchi ${ }^{2}$, Satoru \\ $\mathrm{KANEKO}^{3}$ and HIDEO MOHRI ${ }^{4}$ \\ ${ }^{1}$ Department of Biology, College of Arts and Sciences, the University of Tokyo, Tokyo 153 , ${ }^{2}$ Department of Congenital Abnor- \\ malities Research, National Children's Medical Research Center, Tokyo 154, ${ }^{3}$ Department of Obstetrics and Gynecology, Ichikawa \\ General Hospital of Tokyo Dental College, Chiba 273, and ${ }^{4}$ The University of the Air, Chiba 260, Japan
}

\begin{abstract}
The effectiveness of separation of X- and Y-bearing sperm by free-flow electrophoresis was examined by use of the F-body test and polymerase chain reaction (PCR). For each ejaculate the ratio of $\mathrm{X}$ - and $\mathrm{Y}$-bearing sperm was analyzed by determination of Y-chromosome-specific sequences (DYZ 1) before and after fractionation by free-flow electrophoresis. Fraction number 16 , corresponding to the one peak near the cathode was more than $80 \%$ F-body positive, and the DYZ 1 in it was highly amplified; while fraction number 21 , the peak near the anode, was F-body negative and also DYZ 1 negative. The data were consistent with our previous results; i.e., X-bearing sperm were more negatively charged than Y-bearing sperm.
\end{abstract}

Persistent efforts have been made to obtain male or female offspring by prenatal diagnosis and artificial insemination with $\mathrm{X}$ - or $\mathrm{Y}$-bearing sperm. In human beings, over $200 \mathrm{X}$-linked recessive diseases, typically affecting only hemizygous males, have been identified. For the purpose of therapy, many scientists have developed methods of separating Xand Y-bearing sperm $(4,8)$.

Attempts on the separation of human sperm by means of galvanization have been made by various workers (5-7). The results obtained, however, were in disagreement even when investigators used the same method. The conflict occurred mainly because of the poor methods for detection of X-and Y-chromosomes in sperm. All of these workers used a fluorescence method, in which the F-body, corresponding to a repeating sequence in the long arm of the Y-chromosome, was stained with quinacrine mustard. However, the results obtained by this staining varied depending on the lot number of chemicals, samples, and observer's technique.

Recently, sex-chromosome-specific genes or probes have become available as a consequence of the remarkable developments in human gene map- ping. A Y-chromosome-specific repeating DNA family, determination of Y-chromosome-specific sequences (DYZ 1), was first described by Cooke (2) as a $3.4 \mathrm{~kb}$ male-specific fragment in Hae III digests of genomic DNA. It is a major component of the heterochromatic region of the long arm of the Y chromosome. Nakagome et al. (9) selected useful segments with high male-specificity for polymerase chain reaction (PCR) and made new primers for amplification. In this paper, we applied the PCR to amplify this specific region of the Y-chromosome for evaluating the electrophoretically separated human sperm.

Human semen was collected from healthy men by masturbation after sexual abstinence for at least 4 days. Normospermic semen, which had a density of more than $5 \times 10^{7}$ sperm $/ \mathrm{ml}$ and more than $80 \%$ motility, was used for the experiments.

In order to purify the sperm, the semen was processed by Percoll linear gradient centrifugation and the 'swim down' method previously described (5). The obtained sperm were washed twice with a buffer containing $0.226 \mathrm{M}$ sucrose, $30 \mathrm{mM} \mathrm{MgSO}_{4}$, $0.5 \mathrm{mM} \mathrm{MgCl}_{2}, 1 \mathrm{mM} \mathrm{CaCl}_{2}, 10 \mathrm{mM} \operatorname{HEPES}(N-2-$ 
Table 1 List of Primers Used for PCR

\begin{tabular}{|c|c|c|c|c|}
\hline Locus & Primer & Primer sequence & Location & $\begin{array}{c}\text { Length } \\
\text { (bp) }\end{array}$ \\
\hline \multicolumn{5}{|l|}{ DYZ1 ${ }^{\mathrm{a}}$} \\
\hline \multirow{2}{*}{ A } & Y1-3F & 5'-TCGAGCCCTTTCAATTTGAGTCC-3' & $247-269$ & \multirow{2}{*}{900} \\
\hline & Y1-6R & 5'-AGAATGGACACGAATGCTCAAATT-3' & $1146-1123$ & \\
\hline \multirow{2}{*}{$\mathrm{B}$} & $\mathrm{Y} 1-6 \mathrm{~F}$ & 5'-AATTTGAGCATTCGTGTCCATTCT-3' & $1123-1146$ & \multirow{2}{*}{1024} \\
\hline & Y1-4R & 5'-AATGCCCTTGAATTAAATGGACT-3' & $2146-2124$ & \\
\hline \multirow{2}{*}{$\mathrm{C}$} & $\mathrm{Y} 1-4 \mathrm{~F}$ & 5'-AGTCCATTTAATTCAAGGGCATT-3' & $2124-2146$ & \multirow{2}{*}{1086} \\
\hline & $\mathrm{Y} 1-5 \mathrm{R}$ & 5'-TGTATTAGAATGTAATTGAACTTT-3' & $3209-3187$ & \\
\hline \multirow{2}{*}{$\mathrm{D}$} & Y $1-5 F$ & 5'-AAAGTTCATTACATTCTAATACA-3' & $3187-3209$ & \multirow{2}{*}{647} \\
\hline & Y1-3R & 5'-GGACTCAAATTGAAAGGGCTCGA-3' & $269-247$ & \\
\hline \multirow{2}{*}{$E$} & $\mathrm{Y} 1-1 \mathrm{~F}$ & 5'-TCCACTTTATTCCAGGCCTGTCC-3' & $3511-3533$ & \multirow{2}{*}{323} \\
\hline & $Y 1-3 R$ & 5'-GGACTCAAATTGAAAGGGCTCGA-3' & $269-247$ & \\
\hline
\end{tabular}

a Nakagome et al. (9), Nakahori et al. (10)

hydroxyethylpiperazine- $N^{\prime}$-2-ethanesulfonic acid)$\mathrm{NaOH}$ buffer (pH 7.2), and suspended in $0.5 \mathrm{ml}$ of the buffer.

Separation of $\mathrm{X}$ - and Y-bearing human sperm was carried out in a free-flow electrophoretic apparatus (ACE 710, Hirschmann, Munich) according to the method previously described $(5,6)$.

Human Y-bearing sperm were detected by fluorescence staining with quinacrine mustard dihydrochloride (Sigma, St. Louis, MO) according to the method of Barlow and Vosa (1) with a slight modification (5).

DNA was extracted from the remaining sperm of each fraction and from the unseparated specimen. The sperm, approximately $5 \times 10^{4}$ cells, were incubated in $300 \mu 1$ of a lysis buffer for $90 \mathrm{~min}$ at $37^{\circ} \mathrm{C}$. The buffer was contained $100 \mathrm{mM} \mathrm{NaCl}, 10 \mathrm{mM}$ Tris (tris-hydroxymethylaminomethane)- $\mathrm{HCl}$ buffer ( $\mathrm{pH} 8.0$ ), $9 \mathrm{mM}$ EDTA (ethylenediaminetetraacetic acid), 1.5\% SDS (sodium dodecyl sulfate), $40 \mathrm{mM}$ DTT (dithiothreitol), and $187 \mu \mathrm{g}$ proteinase K. Organic extraction was performed as follows: $300 \mu$ l of water-saturated phenol/chloroform $(1: 1)$ was added to each polypropylene tube. Then, the mixture was vortexed 4 times for $20 \mathrm{~s}$ each time and centrifuged at $12,000 \mathrm{rpm}$ for $10 \mathrm{~min}$ in a TOMY MC-15-A. The phenol extraction was repeated once and followed by extraction with Sevag solution ( $24: 1$, chloroform: isoamyl alcohol). After the organic extractions, the DNA in the aqueous layer was precipitated overnight at $-20^{\circ} \mathrm{C}$ by the addition of $2 \mathrm{vol}$ of $99.9 \%$ ethanol. The DNA was recovered by centrifugation, resuspended in $70 \%$ ethanol for desalting, and then suspended in $60 \mu 1$ of water.

About 100 ng of the sperm DNA from each fraction obtained by free-flow electrophoresis was amplified enzymatically in a $100-\mu 1$ reaction mixture. The mixture was put in a capped $0.5 \mathrm{ml}$ polypropylene tube containing a $1 \mu \mathrm{M}$ concentration of a given set of primers. The reaction mixture contained primers for DYZ 1 (see Table 1), $200 \mu \mathrm{M}$ deoxynucleotides (Pharmacia), 2 units of Thermus aquaticus DNA polymerase (Taq polymerase) (Perkin-Elmer Cetus), $50 \mathrm{mM} \mathrm{KCl}, 1.5 \mathrm{mM} \mathrm{MgCl}$, $10 \mathrm{mM}$ Tris- $\mathrm{HCl}$ buffer (pH 8.4), and $20 \mu \mathrm{g} / \mathrm{ml}$ gelatin, and was overlaid with mineral oil. PCR was performed in a programmable thermal cycler PJ1000 (Perkin-Elmer Cetus) for 25 cycles. Each cycle consisted of $1 \mathrm{~min}$ of denaturation at $94^{\circ} \mathrm{C}, 2 \mathrm{~min}$ of annealing at $60^{\circ} \mathrm{C}$, and 2 min of polymerization at $72^{\circ} \mathrm{C}$. At the end of the 25 th cycle, the samples were held at $72^{\circ} \mathrm{C}$ for $7 \mathrm{~min}$ and then cooled down. Samples were then subjected to analysis by agarose gel electrophoresis either immediately or after standing overnight at $-20^{\circ} \mathrm{C}$.

Eighteen microliters of the PCR product was mixed with $2 \mu 1$ of a loading buffer containing $40 \%$ sucrose, $0.25 \%$ bromphenol blue and $0.25 \%$ xylene cyanol, and electrophoresed in a 1\% agarose gel (SeaKem-LE) containing ethidium bromide using TBE buffer ( $45 \mathrm{mM}$ Tris-borate and $1 \mathrm{mM}$ EDTA) at $90 \mathrm{~V}$ for $2 \mathrm{~h}$.

Five different kinds of primer-sets were used to 


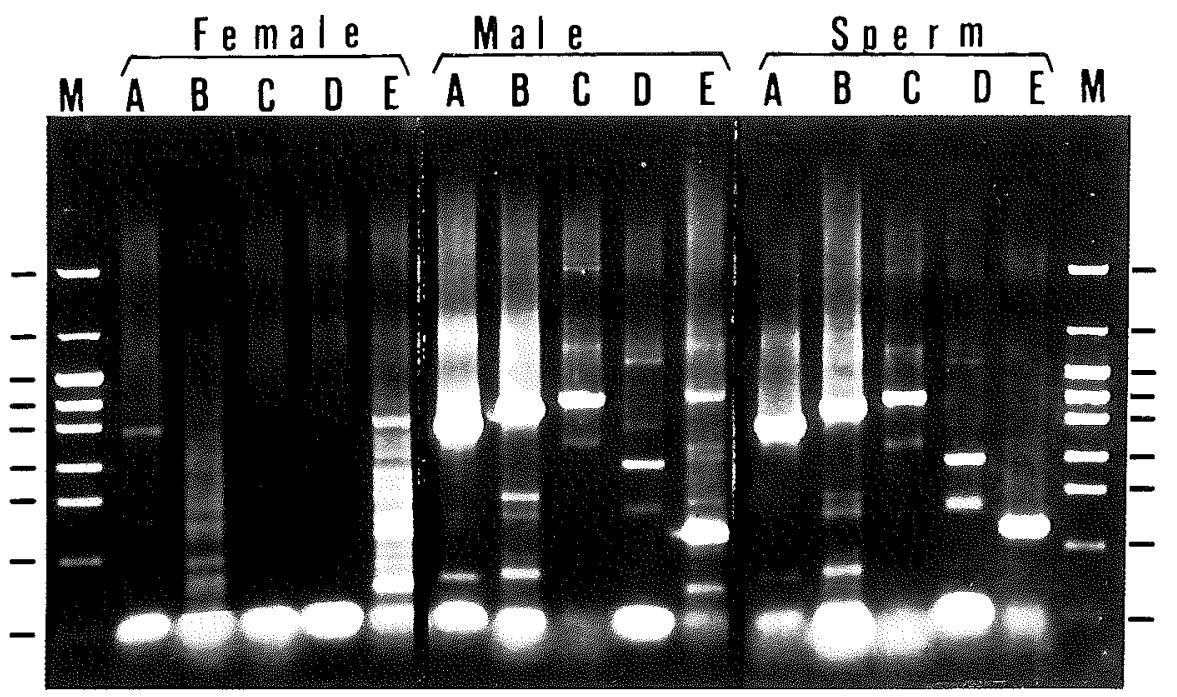

Fig. 1 Ethidium bromide-stained gels of control PCR experiments for frve different segments in DYZ 1 locus (A-E, Cf. Table 1). See text for details. M represents molecular size markers consisting of 4,870, 2,016, 1,360, 1,107, 926, 658, 489, 267, 80 bp (pHY marker: Takara Shuzo, Kyoto, Japan).

Table 2 Characteristics of Sperm Fractionated by Free-Flow Electrophoresis

\begin{tabular}{lcc}
\hline & Fr. 16 (near cathode) & Fr. 21 (near anode) \\
\hline Number of sperm & $4.2 \times 10^{6}$ & $3.5 \times 10^{6}$ \\
F-body test $(\%)$ & 81.4 & 1.6 \\
PCR (cont. $=1.0)$ & 1.15 & $<0.008$ \\
\hline
\end{tabular}

amplify the corresponding segments in DYZ 1 (Table 1). Eight different female blood samples, 8 different male blood samples, and 8 different semen samples were used. Fig. 1 shows one of the typical results in which some segments $(B, C, D)$ were highly male specific, whereas the others (A, E) were shared with female DNA. Multiple bands were observed in both the $D$ and $E$ reactions that were performed with male blood and sperm DNA, or female blood and male blood DNA, respectively. The results obtained for blood cell DNA were in agreement with previous results (9). Sperm DNA exhibited same profiles as male blood cell DNA. We used the DYZ 1B (1,024 bp) fragment primer-set for subsequent experiments because it was highly sensitive and highly specific for male blood cell DNA and sperm DNA, but did not react with female DNA.

Fractionated sperm were counted and smeared for F-body test, and the remainder was subjected to the extraction of DNA for PCR experiments.
Purified human sperm were separated into two peaks under the electric field as described previously $(3,5-7)$. Table 2 shows a typical result of the cell count, percentage of F-body positive sperm, and densitometric analysis of agarose gel after PCR for $5 \times 10^{4}$ cells (densitometric analysis) when sperm were electrophoretically separated into two peaks. Fraction 16, which was a peak near the cathode, was highly F-body positive, suggesting that this fraction was rich in Y-bearing sperm. On the other hand, fraction 21, which was the peak near the anode, was almost negative for F-body, suggesting the presence of few Y-bearing sperm in this fraction.

Fig. 2 shows the results obtained by PCR using DYZ 1B. Single band (1,024 bp) of DYZ 1 was condensed in fraction 16. Fraction 21, on the other hand, was almost negative for DYZ 1. Although the results obtained by PCR were not necessarily proportional to the amounts of template DNA because the control of amplification conditions is 


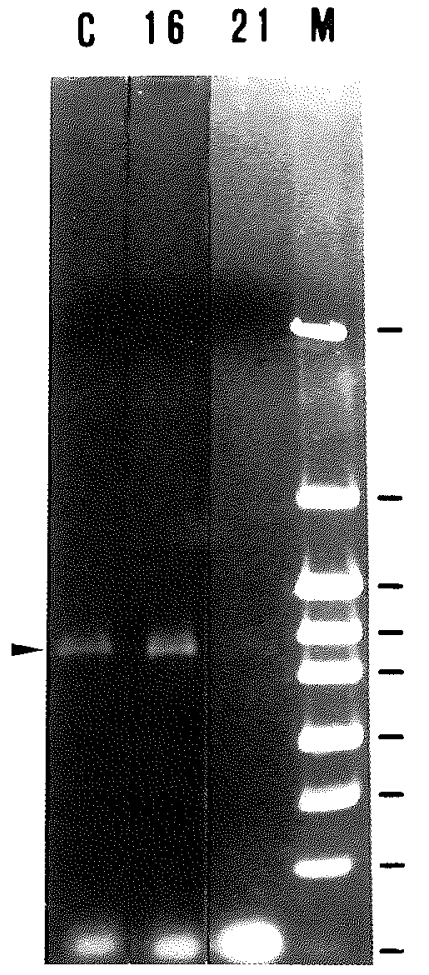

Fig. 2 PCR experiments with unseparated (C) and electrophoretically separated human sperm (16, fraction number 16 near cathode; 21, fraction number 21 near anode) DNA. Each fraction contained DNA from $5 \times 10^{4}$ sperm. $M$ represents the same molecular size markers as in Fig. 1.

difficult, our preliminary experiment for sperm DNA showed that the amount of PCR product was proportional to the amount of template DNA to a certain extent under some limited experimental conditions: Our template DNA was derived from the same number of sperm $\left(5 \times 10^{4}\right.$ cells $)$, and the DNA loaded was less than $100 \mathrm{ng}$ for 25 amplification cycles. The reproducibility of the PCR was confirmed in a calibration experiment from $50 \mathrm{ng}$ to $1 \mu \mathrm{g}$.

The present results are consistent with our previous results (5-7) but conflict with the result of Engelmann et al. (3); i.e., in our hands X-bearing sperm were more negatively charged than Y-bear- ing sperm. The PCR technique proved useful to evaluate the existence of the target sequence in a small amount of DNA sample. This is the first paper showing the application of the PCR to confirm the separation of $\mathrm{X}$ - and $\mathrm{Y}$-bearing sperm.

We thank Dr Y. Nakagome for his valuable discussion. This work was supported in part by grants-in-aid from the Ministry of Education, Science and Culture of Japan for Research on Priority Areas (Nos. 63640001, 01640001,02222101 and 03207101 to H. M. and No. 03207101 to M. O.)

Received 19 March 1992; and accepted 26 March 1992

\section{REFERENCES}

1. Barlow P. and Vosa C. G. (1970) The Y chromosome in human spermatozoa. Nature 226, 961-962

2. Cooke H. (1976) Repeated sequence specific to human males. Nature 262, 182-186

3. Engelmann U., Krassnigg F, Schatz H. and Schill W.-B (1988) Separation of human X and Y spermatozoa by freeflow electrophoresis. Gamete Res. 19, 151-159

4. Gledhill B. L. (1988) Selection and separation of X-and Y-chromosome-bearing mammalian sperm. Gamete Res. 20, 377-395

5. Ishijima S. A., OKuno M. and Mohri H. (1991) Zeta potential of human X-and Y-bearing sperm. Int. J. Androl. 14, 340-347

6. Kaneko S., Irzuka R., Oshiro S., Nakajima H., Oshio S and Mohri H. (1983) Separation of human X- and Y-bearing sperm using free-flow electrophoresis. Proc. Japan Acad. 59, 276-279

7. Kaneko S., Oshio S., Kobayashi T., Iizuka R. and Mohri H. (1984) Human X-and Y-bearing sperm differ in cell surface sialic acid content. Biochem. Biophys. Res. Commun. 124, 950-955

8. Mohri H., Oshio S., Kaneko S., Kobayashi T. and Iizuka R. (1987) Separation and characterization of mammalian $\mathrm{X}$-and Y-bearing sperm. In New Horizons in Sperm Cell Research (ed. Mohri H.) Japan Scientific Societies Press, Tokyo, pp. 469-481

9. NaKagome Y., Nagafuchi S., Seki S., NaKahori Y, Tamura T., Yamada M. and Iwaya M. (1991) A repeating unit of the DYZ1 family on the human Y chromosome consists of segments with partial male-specificity. Cytogenet. Cell Genet. 56, 74-77

10. Nakahori Y., Mitani K., Yamada M. and NaKagome Y. (1986) A human Y-chromosome specific repeated DNA family (DYZ 1) consists of atandem array of pentanucleotides. Nucleic Acids Res. 14, 7569-7580 